\title{
LA INDIVIDUALIDAD VELADA: TITULARIDAD DE DERECHOS EN EL ÁMBITO DOMÉSTICO BAJO EL ORDEN CONSTITUCIONAL DE 1869
}

MARÍA DEL CARMEN SERVÁN REYES

Profesora Asociada de.Historia del Derecho y de las Instituciones Universidad de Sevilla 


\section{SUMARIO}

1. El problema constitucional del Sujeto. 2. El sujeto en la Constitución DE 1869. 3. EL ORDEN CONSTITUCIONAL QUE SE INVIERTE: LA PATRIA POTESTAD. 4. LA LIBERTAD INTERVENIDA: LA PARTICIPACIÓN PATERNA EN EL MATRIMONIO DEL HIJO. 4.1. Fiscalización de la intención. 4.2. Subordinación de matrimonio. 5. TITULARIDAD DE DERECHOS Y LEGITIMIDAD. 


\section{LA INDIVIDUALIDAD VELADA: TITULARIDAD DE DERECHOS EN EL ÁMBITO DOMÉSTICO BAJO EL ORDEN CONSTITUCIONAL DE 1869}

POR

\section{MARÍA DEL CARMEN SERVÁN REYES}

Profesora Asociada de Historia del Derecho y de las Instituciones Universidad de Sevilla

"La familia con el padre, poder, con los hijos, súbditos, y con la mujer, madre de unos y esposa del otron'.

\section{EL PROBLEMA CONSTITUCIONAL DEL SUJETO}

El individuo sujeto y objeto de derechos que presenta el texto constitucional de 1869 en su Título |², dominador pretendidamente del

1 La definición es del diputado Cruz Ochoa, recogida en los Diarios de Sesiones de la Cortes Constituyentes. Dieron principio el día 11 de febrero de 1869, Madrid, Imprenta de J. A. García, 1870-1871; concretamente en la sesión de 22 de noviembre de 1869, Diario de Sesiones número 164, pág. 4341, tomo V.

2 En la elaboración de estas páginas se ha utilizado el texto de la Constitución recogido en la Gaceta de Madrid de 7 de junio (Gaceta de Madrid: Edición microfilmada, Boletín Oficial del Estado, Sección de microfilme). También se ha hecho uso del que aparece publicado en el Diario de Sesiones de 1 de junio de 1869, Apéndice cuarto al número 87, tomo IV. 
orden jurídico en cuanto lo fundamenta y condiciona, responde a la lógica jurídica más exclusivamente individualista, pero también más extremadamente abstracta. La individualidad, sin embargo, podría no ser absoluta, sino condicionada social y políticamente, de ahí que al sujeto en abstracto fuera necesario ubicarlo en aquellas relaciones jurídicas de las que participa, y analizajo bajo los presupuestos de su determinada condición social. De está forma, no habría individuos sin más, sino individuos libres o esclavos, nacionales o extranjeros, padres de familia o sujetos a potestad; es lo que constituye el estado de las personas ${ }^{3}$.

La Constitución parte, al menos doctrinalmente, de la abstracción. Los derechos se presentan como atributos del individuo, producto de una soberanía individual que por primera vez se pretende concurrente con la nacional, y se deduce de la naturaleza humana lo que antes no era sino producto de la voluntad del legislador. Es un planteamiento rompedor, pero no pacífico. No hay en las constituyentes una sola concepción de los derechos, como no hay en la Constitución una única formulación de los mismos. La Comisión Constitucional será, no obstante, tajante: «por primera vez en España, el proyecto de Constitución desarrolla... los derechos individuales, condiciones indeclinables que forman el carácter del ciudadano" y aspira a dar «una norma, que por estar fundada en la naturaleza humana... sirva por largos años al desenvolvimiento de esta Nación» ${ }^{4}$.

Por ello, se renuncia expresamente a la especialidad legal: "Los delitos que se cometan con ocasión del ejercicio de los derechos consignados en este título serán penados por los tribunales con arreglo á las leyes comunes" (art. 23); al sistema preventivo: "No se establecerá ni por las leyes ni por las autoridades disposición alguna preventiva que se refiera al ejercicio de los derechos definidos en este títulon

Sobre las diversas ediciones constitucionales y sus diferencias ortográficas se ha ocupado J. VALLEJO: "Ortografía y heterografía constitucionales (1869)", en Anuario de Historia del Derecho Español, tomo 63-64, Madrid, 1993-1994, págs. 615-699.

3 Es, en definición del momento, la "calidad ó condición bajo la cual se halla constituido el hombre en la sociedad y en su familia gozando de ciertos derechos, acompañados por lo regular de ciertas obligaciones". Diccionario razonado de legislación y jurisprudencia por D. Joaquín Escriche, Madrid, Imprenta de Eduardo Cuesta, 1874, tomo II, pág. 896.

4 El dictamen de la comisión nombrada para presentar un proyecto de Constitución se encuentra recogido como Apéndice al número 37, sesión de 30 de marzo de 1869, tomo II. 
(art. 22); incluso a que en la formulación de los derechos se introduzcan antiguas expresiones que condicionan el ejercicio al arreglo de la ley: Más aún, la opción del constituyente es la de seguir un criterio de formulación de derechos en negativo, que los presupone y garantiza de intervenciones restrictivas. En este sentido se escribe, por tomar el caso más significativo, que "tampoco podrá ser privado ningún español», de los derechos a la libre emisión del pensamiento, reunión, asociación o petición (art. 17) ${ }^{5}$. No se concede el derecho, simplemente se prohíbe su reducción. Es el mismo sentido al que responde el artículo 29 de la Constitución que, fiel al principio de individualidad y libertad, deja abierta la puerta para que se garanticen más derechos de los que se reconocen: "La enumeración de los derechos consignados en este título no implica la prohibición de cualquiera otro no consignado expresamente".

Pero si el sujeto constitucional importa, si importa la abstracción en la Constitución, no es sólo por la concepción que encierra, sino por las particularidades que obvia. La norma fundamental no debería mantenerse al margen de aquellas realidades que conforman el estatuto jurídico del sujeto; realidades que la abstracción puede estar silenciando, pero no por ello eliminando. La indeterminación constitucional podria ser fuente de derechos, o bien estar permitiendo un sistema jurídico paralelo donde los principios constitucionales no siempre prevalezcan.

\section{EL SUJETO EN LA CONSTITUCIÓN DE 1869}

La primera concreción del sujeto constitucional titular de derechos se encuentra en el Título I del Texto de 1869: De los españoles y sus derechos. La condición individual se descubriría, así, insuficiente, y habría de ser completada con la de nacional. Por ello, quienes sean españoles importará, y mucho, a efectos constitucionales, de ahí que su primer artículo se encargue, precisamente, de definirlos. Esta definición, lo sabemos ahora, tendría, de forma indirecta, efectos excluyentes:

5 Para un tratamiento más específico sobre la conceptuación y configuración del derecho a la libre emisión del pensamiento puede consultarse: C. SERVÁN: "Como losa de plomo: el derecho a la libre emisión del pensamiento en el constitucionalismo de 1869 ", en J. M. IÑURRITEgUI y J. M. Portillo (eds.): Constitución en España: orígenes $y$ destinos, Madrid, 1998, págs. 397-423. 
Artículo 1. Son españoles:

1. Todas las personas nacidas en territorio español.

$2 .^{\circ} \quad$ Los hijos de padre ó madre españoles, aunque hayan nacido fuera de España.

3. Los extranjeros que hayan obtenido carta de naturaleza.

$4 .^{\circ}$ Los que, sin ella, hayan ganado vecindad en cualquier pueblo del territorio español.

Pero la lógica constitucional no tiene, como ya se adelantó, un único criterio, o de otra forma no se entiende que, sólo un artículo después, se incluya a aquellos que, por principio, han quedado excluidos:

Artículo 2. Ningún español ni extranjero podrá ser detenido ni preso sino por causa de delito.

Sin embargo, no se considere el precepto como una excepción, sino más bien como un reconocimiento constituyente al individuo no nacional que se hace de forma expresa y cuando al Texto le interesa, como es el caso, hacerle partícipe de derechos. Lo hará también al incluirlos en la redacción del artículo que declara la inviolabilidad domiciliaria: "Nadie podrá entrar en el domicilio de un español, ó extranjero residente en España...» (art. 5), y en el dedicado a la libertad religiosa, aunque en este caso incluso precedan a los españoles, que comparecen de forma residual: «El ejercicio público ó privado de cualquiera otro culto queda garantizado á todos los extranjeros residentes en España... Si algunos españoles profesaren otra religión que la católica, es aplicable á los mismos todo lo dispuesto en el párrafo anterior» (art. 21). Aún más, en un artículo de la Constitución llegan a comparecer en solitario: "Todo extranjero podrá establecerse libremente en territorio español, ejercer en él su industria, ó dedicarse á cualquiera profesión para cuyo desempeño no exijan las leyes títulos de aptitud expedidos por las autoridades españolas»" (art. 25).

Si los derechos fueran individuales en sentido lato, si en el individuo encontraran su fundamentación y a éste correspondiera sin más su titularidad, no tendría sentido la distinción constitucional entre españoles y extranjeros y, todavía menos, lo que, evidente en la redacción de este último artículo, ya no es mero reconocimiento sino verdadera concesión.

Individuos nacionales pues, pero debería añadirse también independientes. No es que expresamente lo reconozca así la Constitución, 
pero su silencio en este caso puede ser tan significativo como en otros su pronunciamiento.

Y ello es así porque, vigente como está en los territorios ultramarinos el sistema esclavista, que reduce a la condición de cosas a aquellos que, como individuos, merecerían ser titulares de derechos, por eso llamados individuales, la hipocresía constitucional, con su silencio, permitió el mantenimiento de una realidad social y jurídica que representaba la negación más rotunda de sus principios. Se pensaba que introducir en la «Constitución un artículo decretando la abolición, sería un lunar en ese Código y la Constitución debe estar limpia de toda mancha" ${ }^{6}$, por ello se descarta el pronunciamiento constitucional y, en su lugar, se extienden a Ultramar los derechos consignados en la Constitución "con las modificaciones que se creyeren necesarias" (Art. 108)7. Ignorada, pero no por ello inexistente, se mantiene así a la población esclava privada del derecho más fundamental a su libertad $y$, junto a éste, la del resto de los derechos mal llamados individuales.

Pero no sería necesario llegar a la privación completa de la libertad que la esclavitud significa para poder ser excluido de la categoría de sujeto independiente. La dependencia no sólo se pierde ante el amo, sino posiblemente también ante el padre o el marido ${ }^{8}$. Es la potestad doméstica la que en este caso impediría, a aquellos que caen bajo su ámbito, cumplir con el requisito constitucional que exige estar en el "pleno goce de sus derechos civiles"

Cuando el redactor constitucional lo incluye en el artículo referente al derecho al sufragio, es plenamente consciente de que está recortando la titularidad del mismo:

6 Es el planteamiento del Ministro de Marina J. B. Topete, expuesto en pleno debate constituyente, en respuesta a una enmienda presentada por F. Garrido en la que se pedía la prohibición expresa de la esclavitud. Diario de Sesiones $\mathbf{n}$. $^{\circ}$ 70 , de 10 de mayo de 1869, pág. 1795, tomo III.

7 Es el artículo que se cita fundamental en la comprensión de la realidad ultramarina. Tienen las provincias de América un tratamiento jurídico específico, que no siempre responde a las categorías constitucionales de los derechos individuales y las libertades. Del caso de Puerto Rico tuvimos ocasión de ocuparnos en: Transposición constitucional en Ultramar o el Proyecto de Constitución de 1870 para Puerto Rico en Historia. Instituciones. Documentos, número 25, Sevilla, 1998, págs. 639-652.

8 En definición de M. ColmElRo, "son independientes las personas exentas de toda potestas doméstica, y dependientes las que viven en la potestad ajenan. Elementos del Derecho Político y Administrativo de España, Madrid, Imprenta de la viuda e hija de Fuentenebro, 1881, 6. edición, pág. 210. 
Artículo 16. Ningún español que se halle en el pleno goce de sus derechos civiles podrá ser privado del derecho de votar en las elecciones de Senadores, Diputados a Cortes, Diputados provinciales y concejales.

Aun partiendo de la restricción general, es preciso detenerse en la repercusión particular. Poner el énfasis en el uso del posesivo "sus», significa reducir el alcance restrictivo del precepto, dado que cada español, según su estado, gozaría de unos derechos civiles determinados: sus derechos civiles. Si lo fundamental, en cambio, es el "pleno goce" de éstos en general, entonces se estaría excluyendo a todos los que, como hijos de familia, quedan bajo la potestad del padre, porque «en España no de halla ninguno en el pleno goce de los derechos civiles, no digo yo á los 25 años, sino á los 30 , á los 40 , á los 50 , ni á ninguna edad, mientras esté sometido á su padre, mientras esté sometido á la patria potestad " ${ }^{9}$. En estricto sentido jurídico, supondría reducir el derecho a potestad $y$ el individuo a autoridad. El sufragio universal es entonces un espejismo, y alli donde se lee español ha de entenderse el padre de familia o el hijo emancipado $y$, aún más, donde se expresa generalidad se adivina género.

En este último sentido, la exclusión de la mujer no es específica, ni podría deducirse de la opción del constituyente por el masculino. Antes bien, podría entenderse que éste fuera, por sistema, género que comprendiera también al femenino y que, para el texto constitucional, españoles lo sean tanto los hombres como las mujeres. La generalidad y no el género sería también lo único coherente con la teoría de los derechos naturales o individuales que la Constitución asume, considerando individuos que no sexos.

$Y$ sin embargo, lo convencional modifica en esta ocasión a lo individual. No se parte de lo igual, sino de lo diferente, hasta el punto de hacer innecesaria la diferenciación entre géneros «cuando el uso y la aplicación común de una palabra (español) la reduce á uno de sus sentidos" y este es, precisamente, el masculino. Que las mujeres tengan derecho al voto es algo "tan difícil de prever" que, en palabras de la comisión constitucional, "no dará nunca origen a anfibologías»10.

9 Es Eduardo Palanca el que así se expresa ante la Cámara constituyente en sesión de 20 de abril de 1869 , recogida en el Diario de Sesiones, ${ }^{\circ}{ }^{54}$, pág. 1216, tomo II.

10 Es hasta tal punto evidente la exclusión, que la corrección que supondría su redacción en masculino «sería más risible que no origen de resultados prác- 
Quedaría por explicar, sin embargo, cómo encaja esta opción en la concepción constitucional de los derechos naturales. Para ello bastarían los argumentos doctrinales del momento que consideran a la mujer, por propia naturaleza, distinta al hombre, en cuanto otras son sus características y otras sus funciones. Esto, en la práctica, supone su ineptitud para «el fin político de determinar el organismo del Estado y la manera de funcionar; no es esa la misión de la mujer en la vida humana»; no es igual su capacidad "por la naturaleza misma de las cosas" ${ }^{11}$. El Estado puede entonces «interpretar con fidelidad las modificaciones impuestas por la naturaleza, reflejando en el Derecho la diversidad de condiciones en que por sí misma se encuentra la persona humana» ${ }^{12}$.

No se estaria asi desconociendo capacidad jurídica a la mujer, sino precisamente reconociéndole la que le es propia. Su posición en la familia y en la sociedad no le permitiría una participación política a través del derecho al sufragio, aunque quizás si una participación politica que podría considerarse de segundo grado, a través de la influencia que ejercen como madres o esposas, principalmente por su papel de educadoras en el hogar ${ }^{13}$.

Pero puede aún partirse de un presupuesto argumental diferente, y no verse alterado el de llegada. Nos referimos, concretamente, a que la exclusión de la mujer seguiría estando justificada con sólo alegar la condición constitucional que exige el "pleno goce de sus derechos civiles». Se entra de nuevo asi en el requisito de la independencia que había significado ya la exclusión de los hijos de familia. No hay mujer independiente mientras esté sujeta a la potestad

ticos". Son todos argumentos de los que se vale la comisión constitucional en palabras de S. Moret y que, además, habrían de tener valor aclaratorio en el caso de que ocurrieran dificultades en la interpretación: "el comentario... resolvería cualquier dificultad que pudiera ocurrir". Diario de Sesiones, $n .^{\circ} 54$ de 20 de abril de 1869 , págs. 1218 y 1219 , tomo II.

11 Seguimos sin apartarnos de los planteamientos argumentales del momento constituyente. En este caso de los diputados F. Romero Robledo y V. Romero Girón, respectivamente, en sesión de 21 de abril de 1869. Diario de Sesiones, . $^{\circ} 55$, págs. 1237 y 1238 del tomo II.

12 V. Santamaría de Paredes: Curso de Derecho Político según la filosofía política moderna, la historia general de España y la legislación vigente. Madrid, Establecimiento tipográfico de Ricardo Fe, 1890, 4. edición, pág. 140.

13 El argumento está claramente formulado en P. F. MonLAU: Higiene del matrimonio ó el libro de los casados, París, Carnier Hermanos, 1898, 10. edición, pág. 26. 
paterna, ni mientras que, como esposa, lo esté a la potestad de su marido ${ }^{14}$.

Tal vez lo que pudiera interpretarse como una posible incoherencia constitucional pueda salvarse si comprendemos al sufragio entre la clase de los derechos políticos, es decir, entre aquellos que se definen por su repercusión social más que por responder a una condición indeclinable de la persona, y que se predican del ciudadano y no del individuo, lo que permitiria, en consecuencia, someterlo a restricciones en su titularidad ${ }^{15}$. El argumento contiene cierta lógica mientras no se ponga en relación con otro artículo también constitucional:

Artículo 26. A ningún español que esté en el pleno goce de sus derechos civiles podrá impedirse salir libremente del territorio, ni trasladar su residencia y haberes á país extranjero, salva las obligaciones de contribuir al servicio militar ó al mantenimiento de las cargas públicas.

La condición comparece de nuevo y con ella las restricciones en la titularidad ya expuestas. La diferencia está en que ahora difícilmente se podría argumentar sobre la base del contenido político del derecho. Más bien al contrario, la libertad de residencia ya había sido reconocida y garantizada de una forma genérica en la propia Constitución:

Artículo 6. Ningún español podrá ser compelido á mudar de domicilio ó de residencia sino en virtud de sentencia ejecutoria.

La concreción habría de significar nuevamente la restricción. El derecho individual a la libertad de residencia termina en el territorio

14 Es una realidad social y también jurídica que pone de relieve C. ARENAL cuando afirma que "las leyes civiles consideran a la mujer como menor si está casada, y aun no estándolo le niega muchos de los derechos concedidos al hombre". La cita, concretamente, se ha extraido de su obra La mujer del porvenir, Sevilla, Imprenta de Eduardo Peiré, 1869, pág. 12. El estatuto jurídico de la mujer en el ámbito civil merecería un análisis propio. Es un tema que se encuentra desarrollado, por extenso, en el trabajo doctoral en curso que, sobre la Constitución de 1869, abarca la concepción de los derechos, la configuración de la justicia y la determinación de la leyes.

15 S. CUeSTA Y MARTín: Elementos de derecho político, Salamanca, Librería de M. Hernández, 1895, 3. ${ }^{a}$ edición; A. PosADA: Guía para el estudio y aplicación del Derecho constitucional de Europa y América, Madrid, Librería de Victoriano Suárez, 1894. Desde posturas más actuales: M. FIOVARANTI, Los derechos fundamentales. Apuntes de historia de las constituciones, Madrid, 1996. 
español; el constituyente lo ha circunscrito al territorio y no a la persona. Los españoles no pueden ser forzados a cambiar de residencia, y hasta ahí el derecho individual; pero sí pueden ser limitados si el cambio se produce por voluntad propia. Es el activo y el pasivo de un mismo derecho pero con un tratamiento jurídico diferente. Lo que genéricamente es un derecho de todos, particularmente es un derecho de algunos, de los que están en el «pleno goce de sus derechos civiles".

La individualidad, hasta ahora contemplada, ha sido velada por la nacionalidad, la independencia o el sexo; la condición civil há suplantado a la condición individual. $Y$ será precisamente esta condición civil la que, a efectos jurídicos, determine la capacidad, sea origen derechos y fuente de obligaciones. Condición personal, pero también jurídica, desde el momento en que los derechos dejan de ser un atributo del individuo para serlo de su estado. Si, además, las circunstancias que a éste constituyen o modifican tienen su base en la ley, pierde el sujeto su soberanía y ocupa el legislador posiciones que le alejan del concepto más básico y primordial de los derechos naturales. Individuo, estado, ley; tres elementos del ámbito civil y no siempre en ese orden.

$Y$ dado que la familia es, en concepto del momento, germen de la sociedad civil, y la sociedad misma, interesa conocer su configuración jurídica, la titularidad de los derechos que se ejercen en su ámbito, dado que podría afirmarse que en ella "se cumple y se realiza el derecho" ${ }^{16}$. La potestad paterna sienta sus bases en un concepto de autoridad que no siempre responde a la lógica más individualista de los derechos $y$, junto a ella, la edad, el sexo o la filiación serán circunstancias decisivas en la conformación del estatuto jurídico de la persona. Todas encuentran en el ámbito doméstico su expresión más significativa, por eso debe el Estado atender a su regulación, porque de otra forma estaría descuidando una parcela de las relaciones juridicas de especial significado en el campo de los derechos civiles.

A falta de un Código que regulara con detalle todas las cuestiones referentes a la persona, las leyes de matrimonio y registro civiles vinieron a constituir un forzado código de familia ${ }^{17}$.

16 V. Santamaria de Paredes, Curso de Derecho político..., op. cit., pág. 103.

17 B. ClaVERo: "Ley de Código: transplantes y rechazos constitucionales por España y Américan, en Quaderni Fiorentini. Per la storia del pensiero giuridico moderno, n. ${ }^{\circ} 23,1994$, págs. 81-194. 


\section{EL ORDEN CONSTITUCIONAL QUE SE INVIERTE: LA PATRIA POTESTAD}

La patria potestad encierra una dimensión moral indiscutible $y$, lo que es más importante, una dimensión jurídica que viene a concretarse en los derechos que el padre tiene sobre la persona y bienes de sus hijos. Estos, en cambio, configuran sus derechos por defecto. El orden constitucional se invierte, y el concepto de los derechos naturales, anteriores y superiores a las leyes, cede su puesto ante una potestad que no se asienta en la individualidad sino en la autoridad. En todo este entramado, es la ley quien determina y configura. Los derechos civiles no son sino los que la ley ha concedido y reconocido en la persona del padre $y$ de los hijos ${ }^{18}$.

El proyecto de Código civil ya tiene este arranque: «Patria potestad es el conjunto de derechos que la ley concede á los padres en la persona y bienes de sus hijos menores" (art. 177) ${ }^{19}$. El último elemento supone, sin embargo, una ruptura revolucionaria de no poca trascendencia. La situación legal del hijo de familia venía siendo la de sumisión al poder paterno más allá del tiempo en el que se alcanzaba la mayoría de edad. Mientras la potestad del padre se interpusiera en sus actos jurídicos y económicos, no le era posible completar su independencia legal y alcanzar el pleno goce de sus derechos.

Hay una proposición de ley en la Cámara que precisamente persigue la declaración de la emancipación legal por la mayoría de edad. Es el único medio de poner fin a la situación existente cuando la regla general es que la "mayor edad no produce la emancipación", lo que significa, para los hijos, "una limitación de los derechos civiles y, por consiguiente una traba para el ejercicio de los políticos». A falta de Código, el artículo del proyecto que vinculaba el fin del poder paterno a la mayoría de edad supondria un remedio para la precaria situación en la que se encontraban los españoles solteros, mayores de

18 T. MARTINez GonzAlez: "De la familia”, en la Revista General de Legislación y Jurisprudencia, tomo 27, 1865, págs. 335-338. En la misma publicación, R. ATARD: La familia ante el Derecho (aspiraciones de reforma), tomo 43, 1873, pág. 224.

19 Proyecto de Libro Primero del Código civil, publicado en el Diario de Sesiones de 21 de mayo de 1869, como Apéndice $5 .^{\circ}$ al número 79, tomo V. Aunque no pasó de ser un mero proyecto, se encuentra en él formulada toda una construcción conceptual sobre los derechos civiles que interesará especialmente a este trabajo. 
edad y no emancipados. Por ello, sería suficiente, según la proposición, poner en vigor los artículos que recogen tal posibilidad (arts. $199.4 .^{\circ}, 208$ y $296.2 .^{\circ} \%$. Interesaba, sobre todo, a efectos electorales donde, como se expuso, la plenitud de los derechos civiles exigida constitucionalmente no se cumpliría en aquellos que se encontraran sujetos al poder paterno. No es de extrañar entonces que, aunque la proposición se tomara en consideración, se decidiera su paso a la Comisión de la Ley electoral ${ }^{20}$.

El fin de este sistema se producirá, no con el Código, que no llega, sino con la ley del matrimonio civil de $1870^{21}$. Entre sus disposiciones, el art. 64 reconoce "emancipado de derecho el hijo legítimo desde que hubiere entrado en la mayor edad". Se ha establecido un límite de tiempo, pero falta la determinación legal de la edad a partir de la cual se haría efectivo. Los veinticinco años parece ser la edad en la que coincide la doctrina 22 , mientras que proyecto de Código civil vendria a fijarla en los veintiuno ${ }^{23}$. La edad vendrá entonces a revelarse condición determinante en la configuración de los derechos civiles de la persona. La mayoría se constituirá en garantía de plenitud juridica e independencia de la potestad ajena. Mientras ésta no llegue, podrá un individuo desempeñar cargos de especial significado en el escenario jurídico y político español, pero siempre bajo la autoridad paterna como hijo no emancipado ${ }^{24}$. Es la inconsecuencia de un sistema legal que permite a los mayores de 21 años ejercer la abogacía y obtener el cargo de procurador y, sin embargo, hasta los 25 años no

20 El texto de la proposición se recoge como Apéndice cuarto al $n .^{\circ} 93 \mathrm{del}$ Diario de sesiones de 7 de junio de 1869, Tomo IV. Su discusión se produce en la Cámara el día 8 de ese mismo mes y se recoge en el Diario de sesiones $n .^{\circ} 94$, págs. 2590-2594.

21 La ley de matrimonio civil se aprobó de manera provisional, «sin perjuicio de las alteraciones que las mismas (Cortes) tuvieren por conveniente hacer en él en su discusión difinitiva». Es lo que establece el artículo primero de la ley de 18 de junio de 1870 por la que se mandan publicar, como provisionales, entre otras leyes, la de matrimonio civil (Gaceta del 21 de junio).

22 Significativo a este respecto es la coincidencia de dos de los diccionarios jurídicos más importantes del momento. Sobre la mayoria de edad pueden consultarse las voces que a este respecto se encuentran en el Diccionario Razonado de legislación y jurisprudencia..., cit., tomo IV, pág. 67, y en el Diccionario de la Administración Española. Compilación de la Novísima legislación de España peninsular u ultramarina en todos los ramos de la Administración Pública. Por D. Marcelo Mar-

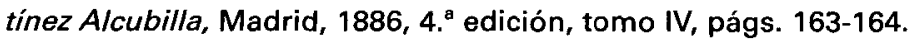

23 Art. 208: La mayor edad comienza á los 21 años cumplidos.

24 P. GonZÁLEZ DEL AlVA: "Consideraciones sobre la mayoría de edad", en la Revista General de Legislación y Jurisprudencia, tomo 42, 1873, págs. 321-329. 
les reconoce capacidad jurídica para personarse en juicio sin la intervención paterna, a excepción hecha de los casados que la tendrían desde los 18 años $^{25}$. Se llega incluso al caso de que, a pesar de requerirse la edad de 25 años para desempeñar el cargo de juez o magistrado, desde los 23 es posible ingresar en el cuerpo de los aspirantes a la judicatura ${ }^{26}$. A efectos matrimoniales, como se verá, será el límite que opere en el ejercicio de los derechos que corresponden al estado civil de casado, y en lo que respecta a la dependencia del poder paterno.

Tanto la edad, como la potestad, habrían de ser determinantes también en la titularidad del derecho al sufragio. El artículo constitucional, como sabemos, permite la limitación al incluir en su redacción la cláusula que exige estar en el pleno goce de los derechos civiles, lo que, en consecuencia, significa la exclusión de aquellos que no han salido de la potestad paterna. El padre es, por defecto, el titular del derecho, y el individuo mayor de 25 años lo es por concesión legal, desde el momento en que es la ley electoral la que expresamente los reconoce como electores ${ }^{27}$. No hay razón de individuo, ni condición natural, sino determinación legal.

Por eso, más allá de la mera fijación numérica, se está resolviendo una cuestión que afecta al sentido mismo de la potestad paterna. Tiene ésta una razón de ser eminentemente moral, orientada a la educación y cuidado de los hijos mientras estos no alcancen su desarrollo físico e intelectual, para lo cual necesitan «del auxilio y protección de los autores de sus días"; llegado el momento en que alcancen éstos la plenitud de sus facultades, la patria potestad carecería de sentido. Es un cambio en los planteamientos que inauguraría el proyecto de Código civil, del que se han tomado las expresiones, con

25 Los artículos 873 y 881 de la Ley orgánica del poder judicial de 15 de septiembre de 1870 (publicada entre los días 15 y 20 de ese mismo mes en la Gaceta de Madrid) exige haber cumplido 21 años para ejercer la abogacia o desempeñar el cargo de procurador. El requisito de los 25 años para comparecer en juicio sin la intervención paterna se recoge, con base en las disposiciones de las Partidas, en el Diccionario de la Administración... cit., tomo 2, 1874, pág. 735. La excepción de los 18 años para el caso de los casados es deducible también de la ley de matrimonio civil que, en su artículo 204, condicionaba las facultades domesticas de los casados sólo hasta esa edad.

26 Artículos 109 y 83, respectivamente, de la Ley orgánica del poder judicial.

27 J. VALLEJO: «Orden, Libertad, Justicia. Figuración constitucional republicana (1873)", en Anuario de Historia del Derecho Español, tomo 67, volumen I, Madrid, 1997, págs. 821-845. 
el que se pondría fin a una etapa marcada por la autoridad desmedida del padre.

Lo importante, a fin de cuentas, es comprender que mientras que la emancipación del hijo no se produzca, sus derechos estarán intervenidos desde una potestad ajena. Cuanto más extensa sea ésta, más reducidos serán aquellos $\mathrm{y}$, en esta relación mutua, es la ley quien impone las reglas. El padre tiene derecho a que los hijos vivan en su compañía, a representarlos en juicio e, incluso, a corregirlos o castigarlos moderadamente (art. $65.1 .^{\circ}$ y $2 .^{\circ}$ de la ley de matrimonio). La ley se ha mostrado, en este último aspecto, más respetuosa con la libertad de los hijos de lo que era el proyecto de Código civil, que ampliaba el poder del padre hasta la posibilidad de retenerlos en un establecimiento correccional. Para ello no era necesaria ninguna diligencia por escrito, sino la orden del padre con el visto bueno del juez. Sólo excepcionalmente habría de motivarse, para el caso de hijos de matrimonios anteriores o cuando estos desempeñaran algún cargo $u$ oficio $y$, en tal caso, el juez ordenaría la detención si encontraba fundadas las quejas del padre (art. 181 y 182). Es la primacía absoluta de la autoridad paterna, por encima incluso de las prescripciones constitucionales que vinculan la detención a la comisión de un delito: « Ningún español ni extranjero podrá ser detenido ni preso sino por causa de delito" (art. 2 de la Constitución) ${ }^{28}$. Si la Constitución había primado al individuo, la ley lo estaría reduciendo a la potestad.

En correspondencia a este derecho del padre, deben los hijos, según la ley, obedecerle si no están emancipados y, en caso contrario, tributarle respeto y reverencia (art. 70 de la ley de matrimonio). No es sólo una obligación moral sino también legal y, en cuanto tal, tiene establecida una sanción penal para el caso de incumplimiento. El legislador ha incluido en el Código penal de 1870, entre las "faltas contra las personas", la que cometen los hijos cuando "faltaren al respeto y sumisión debidos á sus padres», imponiéndoles un castigo de cinco a quince días de arresto y reprensión (art. 603.7. ${ }^{29}$.

28 Recuérdese que el artículo anterior del texto constitucional había comprendido entre los españoles a los «hijos de padre ó madres españolas".

29 El Código penal fue aprobado, provisionalmente, el 18 de junio de 1870, y por decreto de 30 de agosto se dispone su observancia desde su publicación, que tendrá fecha de 31 de agosto (Suplemento al número 243 de la Gaceta de Madrid). El 21 de enero de 1871 se publicará en la Gaceta un decreto que incluye algunas correcciones. 
Por último, también los intereses materiales y económicos del hijo se verán afectados por el poder paterno, a quien la ley reserva facultades en lo que se refiere a la administración y titularidad de los bienes, incluidos los adquiridos por su trabajo o industria ${ }^{30}$.

\section{LA LIBERTAD INTERVENIDA: LA PARTICIPACIÓN PATERNA EN EL MATRIMONJO DEL HIJO}

Libertades reconoce el texto constitucional, lo sabemos ya, en las que la condición de individuo basta para su disfrute: libertad de emisión del pensamiento, asociación, reunión y manifestación, cultos o enseñanza entre otras. Pero hay libertades civiles, las referidas a la vida privada, la persona, su familia y sus bienes ${ }^{31}$, de las que goza el sujeto antes por su condición de estado que de persona. De ahí que el hijo, como se ha expuesto, mientras permanezca dentro del ámbito doméstico paterno tenga su libertad reducida. Otra cosa podría suceder en el caso de que aquél saliera de la órbita de su padre para fundar su propia familia. El matrimonio podría convertirse, entonces, en la condición necesaria para gozar plenamente de los derechos civiles. Pero pudiera ser que el hijo no fuera completamente libre para contraer. Su libertad, también en este caso, podría seguir siendo una libertad intervenida.

\subsection{Fiscalización de la intención}

Antes de que el matrimonio del hijo de familia llegue a celebrarse, cuando éste sólo ha expresado su intención de contraer, reserva la ley un lugar para la intervención del padre. Lo hace al incluir, entre los requisitos necesarios para que el matrimonio pueda realizarse, el consentimiento o el consejo que presta el padre y que ha de presentar el hijo. Requisito previo que la ley reconoce, si no expresamente, sí al menos de una forma implícita cuando se detiene a regular el tipo de papel sellado en que aquellos han de prestarse ${ }^{32}$. Para

30 Los artículos $65.3 .^{\circ}$ y $4 .^{\circ}, 66,67,68$ y 69 de la Ley de matrimonio civil se encargan de regular esa materia.

31 S. CUESTA Y MARTín: Elementos de Derecho político... cit., pág. 66.

32 Orden del Ministerio de Hacienda de 16 de febrero de 1869, publicada en la Gaceta de 5 de marzo. 
conocer con detalle su alcance y formulación ha de acudirse a una norma que se aprueba en una época anterior a la Constitución de 1869. Concretamente una ley de 20 de junio de 1862 establecía las condiciones y requisitos que habían de concurrir en la prestación del consentimiento $y$ del consejo paterno necesarios para contraer matrimonio ${ }^{33}$. Además de su contenido, nos interesa subrayar el hecho de que se considere vigente, y por ello aplicable, una disposición que ha sido realizada bajo un texto constitucional que no es el nuestro, y bajo unos parámetros jurídicos que tampoco son los que nos ocupan. Donde no hubo derogación legal expresa, no la habrá constitucional tácita. El derecho constituyente y el derecho constituido no habrian siempre de coincidir.

Detengámonos, pues, en el análisis del consentimiento y del consejo paterno. De su formulación podría resultar una mayor autonomía del hijo o una mayor intervención del padre. Son dos figuras legales que responden, también, a dos realidades domésticas diferentes. EI primero alcanza a los hijos menores de 23 años y a las hijas menores de 20, y las personas encargadas de prestarlo no necesitan razonarlo aun cuando fuera negativo. En su contra, además, no sería posible interponer recurso alguno (arts. $1 .^{\circ}$ y $14 .^{\circ}$ ). El segundo, por su parte, afecta a los hijos a partir de los 23 años y a las hijas a partir de los 20 sin límite máximo de edad. Tienen uno y otro alcance distinto porque distinto es también su fundamento.

En consentimiento es un acto que depende completamente de la voluntad del padre o de las personas que, en su defecto, se encargarían de prestarlo. Es la "voluntad soberana del padre, digna siempre de atención y de valor y eficacias jurídicas", la que le permite, con su negativa, impedir el matrimonio de sus hijos ${ }^{34}$. El consejo, sin embargo, es el hijo quien lo solicita y, si fuera desfavorable, sólo retrasaría el matrimonio durante tres meses: los que ha de esperar desde la fecha en que se pide (art. 15). Su sentido, probablemente, no sea otro que el de facilitar al padre cierto control o fiscalización en el matrimonio del hijo, a diferencia del poder absoluto que supone el consejo, obstáculo insalvable en la celebración de aquél.

33 Gaceta del 24 de junio de 1862.

34 De otra forma, continúa el autor del que se han extraido las palabras entrecomilladas, "no sería absoluta ó completa» esa autoridad. Es la respuesta de J. M. DE MONER a la pregunta sobre la forma en que han de expresarse el consentimiento y el consejo paterno, y que se inserta en la Revista General de Legislación y Jurisprudencia, tomo 42, 1873, págs. 385-386. La cita, concretamente, en pág. 386. 
Por todo ello, resultaria determinante a efectos jurídicos el conocimiento exacto del momento en que, pedido el consejo, comienza a transcurrir el plazo legal que permitiría al hijo contraer matrimonio libremente. Si el padre se demorara en prestarlo, ya fuera en sentido positivo o, más aún, en sentido negativo, podría indirectamente impedir el matrimonio, dado que al hijo le resultaría muy difícil probar el momento exacto en que se cumple el margen temporal exigido por la ley. Con un fundamento y alcance distintos a los que están en la base del consentimiento paterno, los efectos podrian llegar a ser los mismos.

La ley de 1862 reconoce que el plazo comienza a contar desde la fecha en que se pidió el consejo, pero exige que la petición se acredite, no por quien la realiza, sino por quien «hubiere de prestarlo», ante Notario público o eclesiástico, o bien ante el juez de paz, "previo requerimiento y en comparecencia personal» (art. 15). La cuestión podría resultar dudosa y conducirnos, incluso, a la conclusión de que el consejo, para ser jurídicamente válido, ha de ser expreso ${ }^{35}$, con lo que nuevamente se estaría reduciendo la libertad del hijo para contraer. Una real orden de 16 de diciembre de 1863 puede aclarar las posibles dudas. En su texto se establece que la obligación del hijo está cumplida con requerir el consejo y acreditarlo, porque otra cosa significaría ir en contra del sentido mismo del consejo: «si la negativa del padre al dar el consejo, después de ser solamente requerido, no tienen más virtud que la dilatar por tres meses la celebración del matrimonio, seria absurdo suponer que las evasivas para responder tuvieran más fuerza que aquella, no siendo en rigor más que una forma de negativa» ${ }^{36}$. La ley de matrimonio vendrá a confirmar esta postura al considerar cumplido el requisito legal si los hijos han «obtenido la licencia o solicitado el consejo" (art. 5.3.\%.

Pero, más allá de ser considerados como meros requisitos formales, su falta constituye un verdadero impedimento a efectos legales, porque precisamente entre ellos lo incluye la ley de matrimonio civil: "Aun cuando tengan la aptitud expresada en el artículo precedente, no podrán contraer matrimonio: Los hijos de familia y los menores de edad que no hayan obtenido la licencia o solicitado el consejo

35 Asi lo entiende J. M. DE MONER en respuesta a la pregunta sobre el carácter tácito o expreso del consentimiento y el consejo paterno, publicada en la Revista de Legislación antes citada.

36 El texto de la disposición se ha tomado de P. F. MonLAU: Higiene del matrimonio..., cit., pág. 127. 
de los llamados á prestarlos en los casos determinados por la ley" (art. 5.3. ${ }^{\circ}$. De su carácter especial, fundado en la autoridad paterna, se desprende que no sea posible su denuncia sino por la persona encargada de prestarlos ${ }^{37}$. Así, los jueces municipales habrían de rechazar de plano toda oposición al matrimonio que, fundada en este impedimento, no fuese hecha "por la persona llamada por la ley de 20 de junio de 1862 á dar la licencia ó el consejon ${ }^{38}$.

También el Código penal viene a confirmar la importancia paterna en materia matrimonial. se incluye, entre los delitos contra el estado civil de la persona $y$, concretamente, bajo el concepto de matrimonios ilegales, el de aquellos que siendo menores contrajeren sin consentimiento, castigándoles con la pena de prisión correccional en sus grados mínimo y medio. Sólo la aprobación del matrimonio por quien hubiere de consentirlo produciría el indulto del hijo condenado (art. 489).

Que el legislador está permitiendo este tipo de intervenciones paternas por el respeto que le merece el ámbito doméstico, donde «el carácter de las relaciones que median entre el padre y sus hijos... excluyen la interposición de una tercera personan, no hay por qué dudarlo; de hecho, las expresiones se han tomado directamente del preámbulo que acompaña a la ley de matrimonio de 1870 . Pero que esta participación paterna en materia matrimonial haya de incluirse o no entre los derechos que corresponden a la patria potestad es cuestión más debatida.

De un lado, podría deducirse su exclusión del hecho de que la patria potestad finalice a los 25 años, mientras que el consejo se exige a partir de los 23 años en el caso de los hijos y de 20 en el de las hijas, sin que fije la ley de 1862 límite de edad alguno tras el cual no sea necesaria su concurrencia. Subsistiría así una intervención que, si fuera resultado de la patria potestad, estaría contraviniendo el principio general de la ley de matrimonio. Por otro lado, el hecho de que, en defecto de padre, la ley del 62 haga extensiva la competencia a la

37 Art. 21: Podrán también hacer la denuncia (de impedimentos) todos los ciudadanos mayores de edad. No será admisible, sin embargo, la que se refiere al impedimento expresado en el $n .^{\circ} 3 .^{\circ}$ del art. $5 .^{\circ}$, si no fuere hecha por la persona llamada por la ley á dar la licencia ó el consejo para el matrimonio intentando.

38 Art. $4.1 .^{\circ}$ del Decreto de 16 de agosto de 1870 resolviendo que la ley de matrimonio habría de regir en la península desde el día 1 de septiembre y desde el 15 de ese mismo mes en Canarias, $y$ en el que se dictan varias disposiciones para su planteamiento (publicada en la Gaceta de ese mismo día). 
madre, podria significar también que la facultad de intervenir a través del consejo o del consentimiento no es de las que se comprenden en la patria potestad, ya que en tal caso nunca habria de corresponder a la madre su ejercicio. La adjudicación de la patria potestad a la mujer, aunque lo sea en defecto de padre, es algo que introduce la ley de matrimonio del 70 , pero que desconoce el legislador anterior $^{39}$. Por último, tampoco la referida ley recoge, entre los efectos atribuidos a la patria potestad, el consentimiento o el consejo matrimoniales. Así las cosas, quizás pueda, indirectamente, comprenderse en el artículo que obliga a los hijos menores a "obedecer á sus padres" y, a los hijos emancipados, a "tributarles respeto y reverencia” (art. 70). Por ello, posiblemente lo más correcto sea encuadrar esta facultad paterna entre aquellas que, vinculadas a alcanzar el "bienestar del hijo", se rigen por los "sanos principios de moralidad y justicia» ${ }^{40}$.

Sin movernos aún del momento más primario de la intención de contraer, permitiría el legislador el matrimonio entre el tutor y su pupila si media autorización paterna en testamento o escritura pública. Se admite así, por la sola voluntad del padre, el matrimonio entre aquellos que la ley hace, por principio general, incapaces (art. 6.9. ${ }^{\circ}$ ). Según las palabras del propio legislador, "el grande y profundo res-

39 En defecto de madre se contempla la intervención de los abuelos paterno y materno. Si tampoco ello fuera posible se formará una junta de parientes que, junto con el curador testamentario o el juez de primera instancia, se encargarian de suplir a los anteriores, rebajándose en tal caso a los 20 años la edad de los hijos e hijas que necesitan el consentimiento: "A falta de la madre y del abuelo paterno y materno, corresponde la facultad de prestar el consentimiento para contraer matrimonio al curador testamentario y al Juez de primera instancia sucesivamente... Tanto el curador como el Juez, procederán en unión con los parientes más próximos, y cesará la necesidad de obtener su consentimiento si los que desean contraer matrimonio, cualquiera que sea su sexo, han cumplido la edad de veinte años»" (art. $3 .^{\circ}$ ).

La ley del matrimonio civil dará un paso hacia la integración de la mujer en el ámbito doméstico al concederle, en defecto de padre, la patria potestad sobre sus hijos: "El padre, y en su defecto la madre, tienen potestad sobre sus hijos legítimos no emancipados" (art. 64).

40 Es la postura de L. Rubio y SiBELlo: «De la ley de Matrimonio civil. Después del planteamiento de la ley de Matrimonio civil, inecesitan el consejo paterno los mayores de 25 años, y que por consiguiente están fuera de la pátria potestad?", en la Revista General de Legislación y Jurisprudencia, tomo 40, 1872, págs. 143-146. En lo que respecta a la concepción del consejo no duda en afirmar que «el consejo paterno, lo mismo que el consentimiento, fue un derecho concedido por las leyes independientemente de la pátria potestadn (p. 144). 
peto que merece siempre la potestad paterna, justifican esta excepciónn 41 .

\subsection{Subordinación de matrimonio}

Iniciados los trámites matrimoniales, salvados los primeros obstáculos legales en lo que era sólo la expresión de una intención de contraer por parte del hijo, sus derechos civiles volverán a estar condicionados por la figura paterna. Si se presentara oposición formal a la celebración del matrimonio basada en la concurrencia de algún impedimento, se ordena su comunicación a los contrayentes pero, lo que es más significativo, también a sus padres o curadores si estos fueran menores de 25 años. Aquellos han de decidir si quieren continuar o no con la celebración, pero son éstos quienes se oponen a la denuncia de impedimentos que se tramita en el juzgado municipal42. Sólo ello haría posible que se practicaran, de parte de los contrayentes, las pruebas oportunas que permitieran la desestimación judicial de la denuncia y dejara expedito el camino hacia la celebración ${ }^{43}$.

La situación legal que se produce no deja de resultar paradójica. El mayor de 23 años puede contraer sin consejo favorable de su

41 Es, además, influencia que se debe al Código civil portugués y que se reconoce también el preámbulo del proyecto de ley de matrimonio, del que se han extraído las palabras citadas.

42 Según establece el decreto de 16 de agosto de 1870 sobre aplicación de la ley de matrimonio civil, ratificados los denunciantes en su intención de oponerse a la celebración del matrimonio, vel Juez municipal dictará providencia mandando notificar la denuncia á los que intentaren contraer matrimonio y á sus padres ó curadores si aquellos fueren menores de veinticinco años de edad" (art. 4.3. ${ }^{\circ}$ ). Los interesados, si fueren mayores de 25 años, "y sus legítimos representantes si fueran menores", podrán oponerse a la denuncia (art. 4.4. ${ }^{\circ}$ ). Es disposición que repite el reglamento para la ejecución de las leyes de matrimonio y registro civil de 13 de diciembre de 1870 , publicado en la Gaceta del 14 , en sus arts. $48.3 .^{\circ}$ y $4 .^{a}$

43 El procedimiento se regula con detalle en los números $3 .^{\circ}$ a $11 .^{\circ} \mathrm{del}$ artículo 4 del decreto antes citado. Concretamente en el art. 5 se reconoce que uno podrá procederse á la celebración del matrimonio sin que el Juez de paz á quien corresponda autorizarlo haga constar en el expediente no haberse presentado en tiempo oportuno denuncia de impedimento legal, ó en otro caso que ha sido desestimada por el Tribunal de partido". El que en una norma la referencia lo sea al juez municipal $y$ en otra al juez de paz, se debe a la inclusión, en la ley de matrimonio, de figuras judiciales que estaban, todavía, en la mente del legislador.

Los mismos principios se encuentran en el reglamento de la ley, recogidos en sus arts. 48 y 49 . 
padre, pero no es jurídicamente capaz para hacer oposición a la denuncia que, basa en la concurrencia de algún impedimento, le presente cualquiera. La consecución del matrimonio podría quedar asi a expensas del padre que, no ha podido directamente impedirlo, pero puede utilizar la prescripción legal como obstáculo indirecto a su celebración definitiva.

Aún más, es de suponer que el hijo, una vez ha contraído matrimonio, salga de la potestad paterna para ejercer la que desde ese momento le corresponde como cabeza de familia. En este sentido se pronunció expresamente el Proyecto de libro primero de Código civil, pero la ley de matrimonio guarda silencio a este respecto ${ }^{44}$. Podría, tal vez, deducirse de las competencias que se atribuyen al marido en la administración del hogar y en la persona y bienes de su esposa. Pero es sólo una visión parcial. Si el hijo, aun con la condición civil de casado y los derechos civiles que son propios a su estado, es menor de 18 años, ha de necesitar el consentimiento paterno para administrar sus propios bienes y los de su esposa, incluyendo aquellos actos en los que, como marido, le correspondería representarla en juicio y concederle la licencia para celebrar actos jurídicos y contratos ${ }^{45}$. Tal y como se pregunta en la Cámara el diputado J.A. Bueno, "¿qué es entonces este marido que parece emancipado y está bajo la patria potestad, que parece independiente, $y$ sin embargo permanece en tutela? ${ }^{46}$. La potestad del padre, condicionante de los derechos civiles, se extiende sobre aquellos que como hijos están dentro de su órbita doméstica, y sobre la mujer que, por estarlo en la del hijo, lo está también, por determinación legal, en la del padre.

44 Art. 204: «El matrimonio produce de derecho la emancipación con la limitación establecida en el artículo 80 ". Limitación referida al mantenimiento de la potestad paterna para el caso de que el marido fuera menor de 18 años, y que sí veremos repetida en la ley de matrimonio civil.

45 Art. 45: El marido debe tener en su compañía y proteger a su mujer.

Administrará también sus bienes... y estará facultado para representarla en juicio... y para darle licencia para celebrar los contratos y los actos que le sean favorables.

Art. 46: El marido menor de 18 años no podrá, sin embargo, ejercer los derechos expresados en el párrafo anterior, ni tampoco administrará sus propios bienes sin el consentimiento de su padre; en defecto de éste del de su madre, y á falta del ambos, sin la competente autorización judicial, que se le concederá en la forma y en los casos prescritos en la ley de Enjuiciamiento civil. mo XII.

46 Diario de Sesiones, $n .^{\circ} 280$ de 13 de mayo de 1870, pág. 7951, to- 


\section{TITULARIDAD DE DERECHOS Y LEGITIMIDAD}

Además de todo lo expuesto, donde se ha comprobado que la libertad civil de la persona no siempre se rige por los mismos parámetros que las libertades reconocidas constitucionalmente; que hay derechos que la constitución simplemente reconoce y derechos que la legislación civil concede, es necesario analizar un último aspecto del estatuto jurídico de la persona: aquél que, además de como hijo, lo califica o, mejor incluso, lo cualifica, como legítimo. Atiéndase, en este sentido, a las palabras del legislador en el preámbulo que acompaña al proyecto de ley de matrimonio:»la legitimidad de la prole es la base de todos los derechos civiles que existen en la familia".

La condición determinante en la consideración de la legitimidad de los hijos habria de ser el matrimonio de los padres ${ }^{47}$. En la sección de la ley de matrimonio civil dedicada a la configuración de los efectos generales del matrimonio respecto á las personas y bienes de sus descendientes, ocupa aquella el primer lugar, lo que nos conduce a pensar que sea su consecuencia más inmediata, antes incluso que el establecimiento de la patria potestad, porque precisamente ésta sólo recae sobre los hijos considerados legítimos: «el padre, y en su defecto la madre, tienen potestad sobre sus hijos legítimos no emancipados" (art. 64).

Comencemos entonces por las presunciones legales que, en torno al matrimonio, establece la ley: se presume al hijo como legítimo si aquél existe y si el nacimiento se produce en las fechas determinadas legalmente. El nacido de matrimonio se presume legítimo si el alumbramiento se ha tenido lugar después "de los 180 días siguientes á la celebración del matrimonio, y antes de los 300 días siguientes á su disolución ó á la separación legal de los cónyuges» (art. 56). El nacido en matrimonio, en "los 180 días siguientes a la celebración del matrimonio", se presume, no obstante, ilegítimo (art. 58) ${ }^{48}$. Lo fundamental, a efectos jurídicos, es que la concepción se haya producido mediando matrimonio, de ahí que el plazo mínimo de seis meses, transcurrido desde la fecha de aquel, sea definitivo en la consideración de la legitimidad del hijo.

47 A. Charrin: "De los efectos del matrimonio", en la Revista General de Legislación y Jurisprudencia, tomo 38, 1871, págs. 202-208. En la misma publicación: C. Álvarez: El matrimonio civil, págs. 427-438.

48 El subrayado es nuestro. 
Contra las presunciones, sin embargo, cabe siempre la intervención del marido pero nunca la de la madre. En este sentido, la legitimidad del hijo no podrá ser destruida si no es por la «imposibilidad física del marido para tener acceso con su mujer en los primeros 120 dias de los 300 que hubieren precedido al nacimiento" (art. 56). La declaración que, contra la legitimidad, pudiera hacer la madre, no tendrá valor alguno, ni aun cuando hubiere sido condenada como adúltera (art. 57). Porque ésta desconoce «el misterio en que se envuelve la generación, misterio que la misma madre no puede penetrar", y porque en su debilidad es susceptible de la coacción de un marido que, ofendido en su honra, pudiera arrancarle "una confesión que no se podria saber si tenía de verdadera más que el reconocimiento de la falta cometida" ${ }^{49}$, se la descalifica en una materia que, por afectar a la concepción y al nacimiento, es de suyo más propia de la madre que de un marido que puede no coincidir con el padre. De un lado la debilidad y la ignorancia propios del género femenino la incapacitarian a estos efectos como lo harán también a otros; de otro, la estrecha vinculación entre potestad paterna y derechos de los hijos, y el lugar predominante del varón en el ámbito doméstico, le hacen acreedor de cuantas cuestiones, relacionadas con la legitimidad, tengan consecuencias en el plano jurídico.

Así puede explicarse también la facultad concedida al marido para romper la presunción de ilegitimidad que afecta a los hijos nacidos en matrimonio pero no de él. Si ha sabido del embarazo antes de casarse, consentido a que su apellido sea puesto al hijo nacido de su mujer, o lo hubiere reconocido como suyo, tácita o explicitamente, el nacido habrá de considerarse legítimo a efectos legales ${ }^{50}$. Tampoco importan aquí al legislador la figura materna y su participación en lo que, por sentido natural, es cosa de dos.

49 Se trataría de poner a salvo la legitimidad del hijo de una confesión contraria de la madre, de ahí los argumentos del legislador, arriba expuestos, en el preámbulo que acompaña al proyecto de ley de matrimonio civil.

50 Art. 58: Se presumirá ilegítimo el hijo nacido en los 180 días siguientes á la celebración del matrimonio, á no ser que concurriere alguna de las circunstancias siguientes:

1. Haber sabido el marido antes de casarse el embarazo de su mujer.

2. ${ }^{a}$ Haber consentido estando presente que se pusiera su apellido en la partida de nacimiento del hijo que su mujer hubiere dado á luz.

3. ${ }^{a}$ Haberlo reconocido como suyo expresa ó tácitamente.

Se entenderá que lo ha reconocido como suyo si ha dejado transcurrir dos meses, á contar desde que tuvo noticia del nacimiento, sin hacer la reclamación. 
Podría asimismo el marido, e incluso sus herederos, desconocer la legitimidad del hijo «que la mujer de aquel hubiese dado á luz después de transcurridos 300 días de la disolución del matrimonio ó de la separación». En este caso, y sólo aquí, quedaría a la mujer y al hijo la posibilidad de «justificar» la paternidad del marido (art. 59).

Si nos hemos detenido en exponer los detalles de la legitimidad ha sido porque sus efectos se extienden más allá de la mera condición de la persona en el ámbito doméstico, y alcanzan al individuo como titular de derechos. La ilegitimidad, concretamente, representa un límite e incluso la ausencia de determinados derechos en la esfera civil. Patria potestad, derecho de alimentos, sucesión o herencia, serán algunas de las realidades jurídicas que se verán directamente afectadas. Es más, la extensión de sus efectos se hará depender, incluso, del tipo de ilegitimidad de que se trate ${ }^{51}$.

El proyecto de libro primero de Código civil distinguía, entre los hijos ilegítimos, distintos supuestos. De entre ellos, los calificados como naturales gozaban de una posición ventajosa que podía conducirles, incluso, a su equiparación con los legítimos. La clave vuelve a estar en el matrimonio, al considerarse hijos naturales aquellos que, aun nacidos sin que existiera aquel, fueron concebidos cuando sus padres tenían capacidad jurídica para contraer ${ }^{52}$. Sólo el trámite legal de la celebración les separa de los hijos legítimos, por ello la ley determina que el subsiguiente matrimonio de sus padres conduce a su legitimación ${ }^{53}$. Si tal se produce, serán iguales a los legítimos para todos los efectos legales (art. 149); en caso contrario, su reconocimiento como hijo natural es suficiente para que puedan llevar el apellido de aquel que lo reconozca, recibir alimentos y percibir la porción hereditaria que marca la ley (art. 158) ${ }^{54}$. A falta de una disposición similar en

51 J. ULLOA Y VILA: “Derechos de los hijos sacrílegos en la sucesión de sus ascendientes", en la Revista General de Legislación y Jurisprudencia, tomo 42, 1873, págs. 257-277; A. Charrín: "De los hijos naturales en la sucesión de sus padres», en la misma publicación, tomo 40, 1872, págs. 441-444.

52 Art. 144: Es hijo natural el nacido fuera del matrimonio de padres que al tiempo de la concepción podían casarse por no mediar ningún impedimento de los espresados en los párrafos cuarto, quinto, sexo y sétimo del art. $\mathbf{5 2 .}$

Los impedimentos a los que se refiere son los que afectan a los parientes por consanguinidad $y$ afinidad, a los que profesan como religiosos $y$ a los casados mientras no se disuelva el vínculo.

53 P. GonzÁlez deL ALVA: "El matrimonio civil y los hijos naturales", en la Revista General de Legis/ación y Jurisprudencia, tomo 41, 1872; págs. 273-279.

54 Los arts. 151 a 160 del proyecto de código civil regulan con detalle todos los aspectos referentes al reconocimiento de los hijos naturales, condición impres- 
el ordenamiento jurídico del momento, podría la doctrina recurrir a fundamentos legales de derecho histórico, pero cierto reconocimiento indirecto de la cuestión ya se encuentra recogido en la ley de 1870 del registro civil cuando reconoce la legitimación de los hijós naturales por el matrimonio (art. $\left.67.9 .^{\circ}\right)^{55}$.

El resto de los hijos ilegítimos, a los que el proyecto de Código civil califica de adulterinos, incestuosos o sacrílegos, según procedan de la unión de aquellos que estaban unidos por vínculo anterior, ligados por parentesco o profesaban como religiosos, no podrían ser legitimados ni reconocidos ${ }^{56}$. Su consideración es de upersonas extrañas á sus padres y á sus familias", y sus derechos civiles se reducirían a la prestación de alimentos cuando fuera probada la paternidad o maternidad por sentencia judicial (art. 146).

La nueva ley de matrimonio civil elude cualquier clasificación y contempla la ilegitimidad en general, salvo el caso concreto de los hijos naturales a quienes, por la posición privilegiada que ocupan en el orden civil, interesaría conocer ${ }^{57}$. La ley del registro civil prohibe

cindible para la posterior legitimación: «para que la legitimación tenga efecto, los padres del hijo natural han de reconocerle antes de la celebración del matrimonio ó en el acto mismo de celebrarlon (art. 148).

55 Ley de 17 de junio de 1870 mandando establecer, con el carácter de provisional, el Registro civil en la Península e islas adyacentes (publicada en la Gaceta del 20).

Sobre Registro y derechos civiles: B. Clavero: Código y Registros civiles (1791-1875) en Historia. Instituciones. Documentos, n. ${ }^{\circ} 14$, Sevilla, 1988, págs. $85-$ 102.

56 Art. 144: Es hijo natural...

Es hijo adulterino el que procede de la unión de dos personas que al momento de la concepción no podían contraer matrimonio, porque una de ellas ó ambas estaban casadas.

Es hijo incestuoso el nacido de padres que no pueden contraer matrimonio por razón de parentesco.

Es hijo sacrílego el nacido de padres que la tiempo de la concepción no podian contraer matrimonio por estar ligados, al menos uno de ellos, con el voto solemne de castidad, entendiéndose como tal el solemnizado por la profesión religiosa ó por la recepción del orden sacro.

57 Entre las instrucciones que, por circular de 24 de agosto de 1870, remite la Dirección General de los Registros civil y de la propiedad y del Notariado a los jueces de primera instancia para la aplicación de la ley provisional del matrimonio civil, y a las que acompañan los modelos para la formación de los expedientes, se encuentra, como observación tercera a la redacción del acta de matrimonio, la necesidad de que "en el caso de que alguno de los contrayentes no fuere hijo legítimo, se expresará, en el lugar especial indicado en el acta, que es ilegíti- 
expresamente que en el asiento del nacimiento conste la clase de ilegitimidad, a excepción de los uhijos legalmente denominados naturales" (art. 47.7. ${ }^{\circ}$ ), prohibición y excepción que vuelven a aparecer en el asiento registral del matrimonio (art. $\left.67.3 .^{\circ}\right)^{58}$.

Lo fundamental, en cualquier caso, no es conocer con exactitud la extensión de los derechos civiles de los llamados hijos ilegítimos, sino el constatar que su condición legal representa un recorte en la titularidad de los derechos. Es una condición, además, que no está ligada al individuo por su naturaleza, sino por la nota infamante que la ley confiere a la actitud de sus padres. Ni aun los hijos naturales se libran de la reprobación moral, por eso resultó extremadamente escandalosa la decisión gubernativa que incluía entre éstos a los nacidos de matrimonio sólo canónico59.

mo, diciendo si es natural ó expósito, sin expresar en los demás casos otra clase de ilegitimidad". La disposición aparece publicada en la Colección legislativa de España. Continuación de la Colección de Decretos, tomo CIV (segundo semestre), Madrid, Imprenta del Ministerio de Gracia y Justicia, 1878, págs. 630-648.

58 En los modelos que para la redacción de las actas de nacimiento y defunción se ordenan publicar por la Dirección General, y a los cuales han de ajustarse los jueces municipales, se incluye, en el que se refiere al nacimiento, la prohibición de consignar "la clase de ilegitimidad; a no. ser la de los hijos denominados legalmente naturales" (observación tercera a la redacción del acta). del 23.

La orden es de 22 de diciembre de 1870 y aparece publicada en la Gaceta

59 Esta decisión gubernativa fue originada por una consulta que se eleva a la Dirección general en resulta de un expediente en el que, el juez de primera instancia, se resistió a aplicar la doctrina del promotor fiscal que negaba la inscripción como legítimos de los hijos nacidos de matrimonio sólo canónico. El juez funda su decisión en que "la calificación de ilegitimidad llevaría contra unos y otros una especie de nota infamante". El texto de la real orden de 11 de enero de 1872 reproduce expresamente los argumentos del juez, y se reafirma en la doctrina de que la Ley de matrimonio civil sólo reconoce como legítimos los hijos nacidos de matrimonio que se celebró con arreglo a las prescripciones que en la misma se determinan (Gaceta de 13 de enero).

La cuestión es importante porque se refiere a la pretendida secularización del orden civil que, con medidas como la ley de matrimonio y registros civiles, procura el legislador del momento implantar en el sistema jurídico. Matrimonio católico, registros parroquiales, o cementerios exclusivamente católicos, son algunas de las realidades en la que se asienta el orden civil. El asunto merece un análisis detenido y es materia específica en nuestro trabajo doctoral. Sobre el asunto pueden consultarse: J. ARIAS BRIME: "Matrimonio religioso y matrimonio civil", en la Revista General de Legislación y Jurisprudencia, tomo 43, 1873, págs. 5-9; G. DE AZCÁRATE: Minuta de un testamento. Publicada y anotada por W..., Madrid, Librería de Victoriano Suarez, 1876; I. C. IBAN: "Matrimonio civil y matrimonio canónico en la legislación española (1870-1978)», en Anuario de Derecho civil, tomo 32, 1979, pág. 83. 
No habría argumento legal que permitiera, en un sistema de derechos individuales o naturales, condicionar su ejercicio a una prescripción legal que resultara de prejuicios morales. Ni la titularidad de los derechos debe ser maniatada por la ley, ni las actitudes paternas, consideradas inmorales, producir un menoscabo en el derecho de los hijos. Estos desgraciados hijos - reclama Pi y Margall- "¿vinieron acaso al mundo porque quisieron?"60.

Si en el preámbulo que acompaña al proyecto de ley de matrimonio civil se alude al «derecho sagrado del inocente hijo, cuyo estado civil no debe hallarse á merced de las pasiones de sus padres", lo es sólo en relación al precepto legal que pretende salvar la legitimidad del hijo de la confesión contraria que pudiera hacer la madre. El preámbulo del proyecto de Código civil fue más explícito reconociendo su interés por mantener "la dignidad de la familia» y la "pureza de las costumbres".

Así las cosas, la indeterminación constitucional se ha revelado en concreción de estados; tantos como situaciones jurídicas caben en el ámbito doméstico. Bajo el texto de la Constitución de 1869 se ha ido conformando todo un entramado jurídico que presupone la desigualdad e ignora la libertad. Donde el derecho constituyente sólo considerara derechos, la realidad constituida ha determinado potestades $y$, en la lógica de la ley, la individualidad más abstracta, aquella que haría al sujeto titular de derechos por respeto a su naturaleza humana, ha sido velada por la autoridad, la edad o el género.

El texto constituyente que huía de la concesión, ha presupuesto finalmente la negación. Porque no hay derechos simplemente reconocidos, sino potestades constituidas, las que ejerce el padre sobre sus hijos o, como dejamos apuntado, el marido sobre su esposa; no hay reciprocidad de derechos, sino atribución de condiciones. El estatuto civil de la persona se ha configurado afirmando en unos la autoridad, y negando a otros la libertad.

60 La cita se ha extraído de J. L. LACASTA Zabalza: Hegel en España. Un estudio sobre la mentalidad social del hegelismo hispano, Madrid, 1984, pág. 1256. 